Fecha de recepción: marzo 2012 Fecha de aceptación: junio 2012 Versión final: marzo 2013

\section{Rapsodia para los sujetos por sí-mismos. Hacia una sociedad de localización participante Alfredo Gutiérrez Borrero *}

\begin{abstract}
Resumen: En esta subjetiva, personal, localizada y participante meditación sobre sujetos y subjetividades, refiero mi experiencia educativa con estudiantes de diseño industrial de la Universidad Jorge Tadeo Lozano de Bogotá, Colombia, de la misma asignatura: Investigación para Proyecto de Grado (IPG), tras casi tres años (2009-2012) dedicados a propiciar conversaciones y aproximaciones en el aula, en dinámicas que denomino de diseño de comunidades para consolidar fuertes vínculos intersubjetivos. Mi argumento, no lineal, sino fragmentario y circular (de ahí el nombre "rapsodia"), lo planteo desde autores a quienes considero defensores, tanto de la subjetividad como de sujetos empíricos con nombre y apellido (Alain Touraine, Judith Bulter, Boaventura de Sousa Santos, Tony Fry, Klaus Krippendorff, Judith Bulter, Veena Das, Clifford Geertz, etc.). Los cinco cantos: 1. El consumo de la personalidad, 2. Artefactos y no objetos. 3. Diseñar como condición de subjetivación, 4. Los cuerpos en las palabras y 5 . Las palabras en los cuerpos, constituyen un manifiesto que elaboré en primera persona (localización participante) para explicar el porqué considero que todo diseño, cuanto más profesional más subjetivo e intersubjetivo, surge del encuentro entre personas asimismo localizadas y participantes.
\end{abstract}

Palabras clave: 'compluridad' (como pluralidad) - diálogo - diseño - lenguaje - participación - sujeto.

[Resúmenes en inglés y portugués en la página 289]

(*) Zootecnista (UNISALLE). Especialista en Docencia Universitaria (UMNG). Maestría en Estudios de género, en curso (UN).Escritor y columnista sobre la pertinencia del Diseño. Docente e Investigador, Programa de Diseño Industrial (UJTL) Bogotá.

\title{
Proemio
}

Soy aquí irremediablemente subjetivo, autor del cuento, responsable de los daños que cause o los beneficios que aporte: si no puedo serlo en un texto donde están condensadas reflexiones acerca de la subjetividad contemporánea ¿dónde entonces? Ahora bien, salvo para quienes conozcan y, más aún, hayan vivido en iguales épocas los mismos escenarios (y ni tal vez así, pues entonces tendrán impresiones propias al respecto) contextualizar los párrafos siguientes en el ambiente de mi relación particular como educador, entre 2009 y 2012, con estudiantes de diseño industrial, en diversos grupos, durante la elaboración de sus proyectos grado, en aulas 
de clase de la Universidad Jorge Tadeo Lozano de Bogotá, Colombia, siempre en el marco de la asignatura de Investigación para Proyecto de Grado (IPG), con intención de propiciar comunidades de sentido, es labor muy esquiva.

A despecho de cuanto yo pueda exponer.

Para ser sincero, encuentro imposible que las personas comprendamos del todo las conversaciones en que no participamos. No obstante, estimo que sí podemos compartir impresiones al respecto y conversar sobre las versiones que relatamos unos y otros de prácticamente cualquier asunto, vivo la realidad como algo construido y actuado de diverso modo por cada quien; así, escribo desde mi lugar bogotano y colombiano, a comienzos de la segunda década del siglo XXI, con mis valores explícitos en cada palabra: muestro lo que considero pertinente y aquello de lo cual me aparto, de modo deliberativo. Retórico. Discursivo. Dialógico. Pasional. Visceral incluso. No sistémico, ni objetivo. Más opinión y juicio que verdad. Más doxa que episteme (de hecho casi toda episteme, la comprendo como doxa de personas determinadas con suficiente influencia y credibilidad ante terceros para hacerla pasar como tal en cierto instante por algún tiempo). No prevengo la teoría como ley ni destino ineludible, sino como sugerencia; y la ciencia, aun la más dura, como otra narrativa humana más, tal cuales son la política, la economía, la filosofía etc. (que tampoco son señoras que obren solas sino que toman cuerpo en mujeres y hombres economistas, políticos, filósofos, etc., que las hacen obrar). Por eso la voz pasiva impersonal ("se piensa", "se ha visto") la cuestiono -al igual que lo hacen desde sus textos todos los autores que cito- como a una estratagema. Subterfugio. Pretexto para que científicos, expertos y profesores dogmaticen desde ninguna parte y desaparezcan las voces de los teorizados, estudiantes, gente del común, o gentes de otras culturas, bajo supuestas normas universales, dadas en algún momento, desde alguna parte y con algún interés por personas con intenciones diversas y el distintivo común de intentar que todos aceptemos una sola realidad; y bajo aquel paradigma prevalente según el cual los observadores no podemos entrar en las descripciones y construcciones de nuestras observaciones ( $c f$. Krippendorff, 2009, pp. 12-19). La voz personal es para mí imprescindible, y más en el tema que trato aquí, la articulación de comunidad, no quiero expresarme como un libro, sino como un ser humano. Al decir "yo pienso" me responsabilizo por lo dicho, sin ampararme en datos mágicos que pueden hablar ("no lo digo yo, lo dicen los datos"): por algo, se llaman hechos, no como observadores, sino como participantes humanos los hacemos. Estoy en un lugar, y reivindico mi derecho (y el de todos los humanos) a expresarse desde alguna parte, no comprendo visión sin vidente, ni conocimiento sin cuerpo, y sólo puedo enunciar desde donde estoy, tratar de discurrir desde varios puntos y sopesar las dicotomías, sería aquí un despropósito; más que héroes o villanos, relato desde ejercicios de diseño de comunidad, las vivencias y los argumentos por los cuales considero que en la educación en diseño la presunción de objetividad y el ocultamiento de la incidencia humana restan oportunidades a quienes practican la profesión, y a través de ellos a todas las personas; prefiero contemplar el diseño como algo subjetivo, intersubjetivo, pleno de transitorias verdades conversacionales, donde se cruzan numerosas versiones. He empleado paráfrasis a lo largo del escrito, esto es: citas no textuales, de casi todos los autores, en razón de ello, quien lea encontrará por doquier la abreviatura $c f$. del latín confer, correspondiente en español a "compárese con". Consignado lo anterior, pleno de valores y apreciaciones personales, que a nadie deseo imponer, sino compartir a quien le interese para concordar o discrepar, empiezo a fungir como rapsoda, a ensamblar canciones y trozos de poemas, a fusionar y recombinar, a tomar prestados 
versos o hurtarlos ( $c f$. Rapsodia-eti., s.f., s.p.), a servirme de sentencias y expresiones ajenas ( $c f$. Rapsodia-sig, s.f., s.p.), cual antiguo cantor romántico para estructurar diferentes segmentos temáticos con desenvoltura y a veces sin relación manifiesta entre ellos (cf. 'Rapsodia', 2011, s. p.), tal es mi rapsodia para los sujetos por sí-mismos.

\section{Canto primero: el consumo de la personalidad}

Estimo el sí-mismo como meta vital, expresión cabal de la combinación que buscamos como destino en tanto personas singulares, y para las comunidades que integramos al conformar totalidades vinculadas ( $c f$. Jung, 2009 [1928], p. 210). Mi contexto es el aula de diseño, bien académica donde me co-educo con quienes diseñarán profesionalmente, bien Bogotá como aula multitudinaria donde vivo como estudiante y profesor permanente. Incluso la sociedad colombiana como artefacto diseñado, donde nada es dado (naturaleza, principios, conciencia) sino elaborado a partir de acciones dirigidas a la creación de cada yo por sí-mismo, desde resistencias, insistencias, y deseos reflexivos participantes (cf. Touraine, 2000, p. 280). "Ha sido estipulado que sólo vemos lo que miramos y sólo miramos lo que queremos ver" (Bertillon A. en Virilio P., 1994, p. 42). Todo depende de que nos dejen.

Desde junio de 2009 he guiado grupos pertenecientes a la asignatura de Investigación para Proyecto de Grado (IPG) en el Programa de Diseño industrial de la Universidad Jorge Tadeo Lozano. Durante nueve ciclos, junto con los estudiantes hemos desarrollado un ejercicio con el continuo propósito, de ir más allá de describir realidades. La historia colectiva (y por supuesto personal) acontece en el marco de la elaboración del proyecto de grado (trabajamos en el penúltimo curso del plan de estudios) a partir de lo autobiográfico. Intentamos cambiar realidades - pues presumimos más de una- desde el carácter de cada quien y la validación de la propia experiencia, con ánimo de eludir el filtro del fenómeno impersonalizado. Quien toma la asignatura ha cursado, para dicho momento, cuando menos cuatro años de otras asignaturas y busca conocimiento humano accesible para diseñar; por diversas rutas, algunas distintas a la objetiva reflexión del intelecto protocolar (usualmente el del profesor). Me interesó que todos consigan plasmar mundos éticos no regulados por razones universales, ni esquemáticas. Ocasionalmente eso implica vencer las aduanas del método de quienes relativizan la experiencia; para devolver valor a lo inmediato, a la agencia de cada estudiante en el diseño de su historia (cf. Negri y Hardt, 2000, p. 64).

En solitario nadie, estudiante o profesor, inventó el mundo, ¿cómo puedo 'yo' apropiarlo? Nuestro gran reto fue conseguir implicarnos en la experiencia, pues quienes diseñamos no somos sujetos pre-elaborados a quienes la experiencia nos suceda o pueda sernos atribuida. De todos modos, si nuestra humanidad, nos hace tan complicados como para tener un lenguaje como condición de la experiencia ipor qué no hablar? (cf. Das, 2007, p. 4).

Durante los primeros ciclos del experimento, estábamos separados juntos, nos sentábamos en círculos donde cada quien presentaba los ejercicios que conducían a la formulación de su proyecto. Pasados los años, reconozco cuán difícil fue forjar aproximaciones, dada esa tácita predisposición de cada quien, para intentar ser el mejor en solitario, internalizada tras innumerables clases previas donde eran privilegiados "aprendizajes insociables"; por aquella noción prevalente del diseñador genio. No obstante: "es un hecho que todos los diseñadores, tanto los diseñadores 
extraordinarios, como los mediocres, siempre construyen, modifican y continúan el trabajo de otros diseñadores, y que nadie puede evitar hacer eso" (Michl, 2008, s.p.); por ende, apoyé la construcción de comunidad que sólo acontece entre personas: "durante mucho tiempo el sujeto fue sustituido por el objeto, ahora el sujeto debe volver" (Touraine, 2000, p. 249). Tradicionalmente en el diseño industrial de nuestro programa, como lo he vivido desde 1993, la noción del objeto dominó el panorama: el objeto comunica, el objeto habla y "te dice" (o "le dice" a, quien quiera que sea "el usuario") cómo manejarlo, amonestan muchos profesores.

Cabe anotar que la ciencia generalista y universal, la vivo como otra respetable narrativa más entre muchas coexistentes (arte, religión, tecnología, política, magia, etc.), por ello considero que las generalizaciones universales son lugares epistémicos ambiguos, útiles para comprobar pero estorbosos para ver casos puntuales como las coordenadas del sí-mismo. Toda generalización (incluida esta) involucra o injusticias o estupideces. Los seres humanos vivimos entre artefactos materiales, con los que instauramos relaciones objeto/sujeto. Para diseñar, buscamos la frontera entre presencia física e imagen visual; entre las propiedades reales del material y sus mitos circundantes; entre la particularidad empírica y la representación teorética ( $c f$. Attfield, 2000, p. 11). Más que de sujetos, hablo de Jorge Aristizabal, Laura Acevedo, Hernando Granados o Lina María Rodríguez, estudiantes con quienes trabajé, compartí y discutí; y aun lo hago. No mariposeo sobre los intríngulis del sujeto metafísico del viejo Kant, controlado al vaciar la experiencia en el fenómeno, al circunscribir el conocimiento a la estandarización intelectual y al neutralizar la posibilidades de acción ética mediante razones esquemáticas ( $c f$. Negri y Hardt, 2000, p. 66).

Difícil como es, adelantamos un trabajo de diseño de comunidades, en el cual la gente en cada grupo, primero por sugerencia mía, y crecientemente a ejemplo de lo hecho en y por grupos anteriores, buscó construir en solidaridad, los estudiantes intentaron apropiar las relaciones existentes entre su situación, vivida al formular un proyecto, y la vivida por otros en circunstancia similar: existimos personalmente en la sociabilidad (cf. Touraine, 2000, p. 272).

Mis canas aumentaron, y mi calva se expandió en un entorno académico donde discurrir en primera persona es tabú, y donde muchos diseñadores industriales (y diseñadoras industriales, pues las mujeres son mayoría) se enojan al escuchar expresiones como "diseño de sonrisa", y asumen que las gentes comunes ("no-diseñadores") afrentan su quehacer si osan emplear la palabra diseño. Pero las palabras son de la humanidad; es más, todos los seres humanos diseñamos, incluso macacos y chimpancés elaboran artefactos para lograr fines ( $v$. Nitzche, 2012, s.p.). Nuestra subjetividad, el sí-mismo, emerge cuando interactuamos con materialidades e inmaterialidades, al diseñar, al hacer "cosas con actitud", y crear con fines específicos en mente, o buscar consumar tareas particulares, o manifestarnos para objetivar valores morales, expresar identidad individual y grupal, denotar estatus, pavonearnos de proezas tecnológicas, ejercitar control social, u ostentar poder político ( $c f$. Attfield, 2000, p. 12).

Subjetividad de subjetividades y toda subjetividad. Con Touraine, pienso que los sujetos chocamos con la sociedad de consumo (de las personalidades ante una objetividad que es todos y nadie), (cf., 2000, p. 249). Singularmente, muchos diseñadores industriales en las aulas tadeístas en que he vivido (no las que SON sino las que recuerdo y percibo) se preocupan por diseñar cosas para una sociedad de consumistas, ¡que nada consumimos! Llamamos 'consumo' a la adquisición de mercancías, mientras nuestros hogares pobres o ricos, alimentan continuamente basureros, rellenos e incineradores: colchones viejos, sillas rotas, carcasas de computadores, 
teléfonos y televisores, ollas abolladas, bolsas plásticas, empaques, calentadores oxidados, neumáticos viejos, baldes sintéticos quebrados, zapatos semiderruidos, pura materia 'inconsumida' (sea esta desperdicio o no) ¡una oda a lo insostenible! (cf. Fry, 1999, p. 108). Así, lo único consumido en la sociedad de consumo académica, es el derecho de cada quien a 'autobiografiarse' al diseñar.

Con eso en mente, durante los nueve ciclos de IPG que acompañé, busqué alentar a los estudiantes a conversar para hacer circular información construida por ellos, y posesionarse cada uno de su papel comunicativo (cf. Touraine, 2000, pp. 272-273).

\section{Canto segundo: artefactos y no objetos}

Como reto docente, propuse a los estudiantes asumirse como sujetos emancipados del individuo objetivo construido desde categorías generales y perfiles mercantiles; autoconstruirse sin interiorizar preceptos obligatorios mediante el diseño conjunto de sus proyectos y conversar para entrelazar individualidades ( $c f$. p. 274). Los aciertos y errores fueron valorados por decisión propia. Diseñamos dando valor a las cosas, ¡otorgándoles sentido humano!, anoto en confesado pastiche de Nietzsche, para quien 'hombre' traducía 'valorador' (mensch palabra alemana para hombre, la derivaba del latín mensuratio: medida). Valorar es diseñar, y diseñar optar. Por valoración subjetiva, diseñamos; sin ella la existencia estaría vacía. Cambiar de valores, es cambiar de diseño. Diseñadores fueron primero grupos, y después individuos ( $c f$. Nietzsche, 1982, pp. 58-60 \& Nietzsche, s. f., pp. 33-35).

En febrero de 2011, con los integrantes del sexto de los grupos que acompañé en IPG, implementamos la modalidad de nominar el colectivo, 6 hombres y 8 mujeres eligieron como nombre Tinkuy, vocablo quechua para 'encuentro'. Dicho acto sencillo permitió caracterizar más su comunidad. Es difícil auto-diseñarse (poiesis) fuera de un paradójico modo de subjetivación impersonal, las normas constriñen las posibles formas por la cuales podríamos optar ( $c f$. Butler, 2005, p. 17), por ende, el siguiente paso fue matizar el discurso objetual. Toda narrativa puede ser contrastada: usamos artefactos cuando hacemos interfaces con ellos. Desde discursos de diseño objetivistas producimos objetos, pero cuando mediante un giro semántico personalizamos, y experimentamos reiterando interacciones estables y fiables, lo que diseñamos son artefactos (de 'ars', 'destreza' y 'factum', 'hecho': hechos-con-destreza). Los Tinkuy (8 mujeres y 6 hombres) cuya metáfora fue tribal, proyectaron hacer artefactos, configurarlos materialmente, reconocerlos conceptualmente, interactuar con sus proyectos en interfaces que de funcionar como subjetivamente deseaban suministrarían ('afordarían') lo que era esperado al usarlos. Tal cual señala James Gibson (1979), cuando lo diseñado no funciona según esperábamos sin que entendamos porqué, 'objeta' que lo empleemos ( $c f$. Krippendorff, 2007, p. 4).

Las asignaciones de clase de la tribu Tinkuy requerían relación entre compañeros (conversar, preparar, organizar, etc.). Inicialmente algunos estudiantes sufrieron: "el exceso de trabajo grupal, que nos impide hacer nuestros proyectos", mas el gran proyecto estaba en generar lazos para diseñar en compañía: realizarse como sujetos en la inestabilidad y el desequilibrio del encuentro, afrontando lo que media entre comprometerse y desligarse de responsabilidades. Simultáneamente con la mayor fuerza y la máxima fragilidad ( $c f$. Touraine, 2000, p. 280).

Vivimos entre límites difusos, ¿dónde está el punto preciso en el transcurso de nuestra vida en 
que podamos decir, "desde aquí fui sujeto"? Construirnos en comunidad implica aceptar que estamos abiertos, nunca hechos del todo. Valoramos, atribuimos significados, trazamos fronteras: la experiencia de nuestro límite es encontrarnos ( $c f$. Das, 2007, p. 4). Insisto cuando diseñamos objetos para uso universal y único en mente, imponemos a otros seres humanos modos de usar lo cual (objeta) su agencia. Similar acontece con el profesor que constriñe a todos los estudiantes a diseñar de igual modo. En alemán, objeto es 'gegenstand': algo arrojado en nuestro camino que opone resistencia. Por ende, aquellos objetos que 'dicen' unívocamente cómo usarlos los considero fascistas y opresivos, tanto como a los profesores cuando monologamos (como yo en este texto). Prefiero la concepción de Gibson de 'afordancia': no hay conocimiento privilegiado de los objetos de un mundo externo único, conocemos según concebimos lo exterior y a los demás al interactuar con ellos. Sin verdad implícita, solo con afordancias o su ausencia ( $c f$. Krippendorff, 2007, pp. 4-5). Las 'afordancias' son posibilidades de uso múltiple en nuestro encuentro con los artefactos y el entorno. Involucran contextos y personas. Para diseñar comunidad propongo aproximar sujetos y artefactos ( $c f$. Gibson, 1986, p. 127), no pensar en objetos. Las afordancias son objetivas, reales y físicas (pero les atribuimos significados subjetivos, coyunturales, mentales); así no son objetivas ni subjetivas, o son ambas a la vez. La dicotomía subjetivo-objetivo soporta la insuficiente generalización de la tontería. Es nuestra participación en el contexto, a la par ambiental y conductual, física y psíquica (e irreductible a polaridad alguna) donde acontece el diseño ( $c f$. p. 128).

Como sea, nuestra iniciativa de generar comunidades encontró oposiciones de quienes se quejaban o porque no la veían pertinente (usualmente profesores), o porque no la vivían aún (como pasó con estudiantes que cursaban la misma asignatura en otros grupos). La novedad encuentra dos adversarios: quienes la descalifican y quienes censuran a quienes la impulsan porque no beneficia a todos, sin advertir que, como novedad, está recién inventada e intentada. Para diseñar valen menos las leyes científicas que las del derecho, estas últimas articulan comunidades. Por cierto, cuando varias personas intentan fijar normas sobre lo bueno y justo, como pasó en los grupos de IPG tadeístas cuya experiencia comento, emergen conflictos y distancias. Lo cual relaciono con una asignatura, aún presente en nuestro plan de estudio tadeísta en diseño industrial que llamamos "lenguaje y significado del objeto", su nombre me parece ratificación de insólitas prácticas educativas donde los objetos pueden hablar. Pero los estudiantes no. A Tinkuy, tras una ceremonia de despedida a la cual asistieron exalumnos, profesores y hasta una madre de familia, lo sucedió en el séptimo ciclo, otro grupo de IPG. Como cada periodo organizamos un encuentro: los del grupo entrante, fueron visitados por el saliente. Unos relataron experiencias, otros, expectativas. Así modelamos el concepto comunal. Considero a cada grupo bosquejo de lo que podría ser una comunidad viable. Llegado el tiempo, los integrantes del nuevo curso optaron por la designación de Alpha18 (15 de 18 eran mujeres), su objetivo radicó en entonar una melodía conjunta: cada quien dirigía su proyecto e interpretaba para los ajenos. La metáfora fue musical, su nombre aludía a una orquesta bogotana: Los Alfa8.

Algunos aman el dominio, otros el sometimiento, y hay quienes soñamos áreas libres sin mandamases, ni subalternos. En aulas donde los profesores monologan ante los estudiantes sin propiciar que dialoguen entre sí, las comunidades no son promovidas. Sino destruidas. Me inquieta encontrar aún, en últimos cursos, notas pegadas a la puerta de los salones con letreros como: "el profesor no viene. Hoy no hay clase". ¿Acaso los estudiantes no cuentan? ¿Qué clase de clase es aquella donde sólo el profesor es "clase"? (En el Diccionario de la Real Academia 
Española están consignadas dos acepciones de clase, desde la primera, clase es "la lección que da el maestro a sus discípulos", pero desde la otra es también el "conjunto de estudiantes que asisten al aula", según esta última si hay estudiantes hay clase: con o sin profesor).

Quizá el agrado de ser manada antecedió al disfrute de ser yo. Y, como señala el filósofo, en las aulas, cuando la buena conciencia es rebaño, la conciencia perversa es yo. O viceversa. Como fuere, los discursos de quienes demandan hablar en impersonal, los vinculo con un tipo de docente astuto, poco amoroso, cuya versión consume las versiones de muchos, docente que en lugar de originar asociaciones, propicia separaciones. Que más que oír, quiere oírse.

Amantes fueron siempre, y creadores, los diseñadores de cuanto se usó bien y cuanto se uso mal. Llamea el amor al proyectar novedades, y a veces también la cólera ( $c f$. Nietzsche, 1982, pp. 58-60 y s.f., pp. 33-35). Ahora bien, para muchos colegas "el diseñador" no debe hablar 'carreta' (más aún, ni siquiera debe hablar), solo dedicarse a lo suyo: a diseñar. Pero con la tribu Tinkuy y la orquesta Alpha18 empezamos a diseñar con el lenguaje (cf. Das, 2007, p. 4); a veces, pensamos y actuamos como si fuéramos nosotros quienes mandáramos dicho lenguaje, pero a menudo es 'él' quien nos manda a nosotros ( $c f$. Fry, 1999, p. 174). Los productos del diseño son fruto del lenguaje y significado sí, pero no del objeto, sino de quienes conversan con otros para diseñarlos. El lenguaje nos vincula, vivos. Hasta eso 'indecible', cuando ignoramos qué decir, es un modo de 'lenguajear', útil para comunicar solo en los laberintos lingüísticos, allende los cuales no hay 'indecibilidad’. Fuera del lenguaje, acaso, sólo está la muerte” ( $c f$. Mires, 2002, p. 196).

\section{Canto tercero: diseñar como condición de subjetivación}

Hay una tradición epistemológica proscrita la modernidad, pero validada por teóricos de la crítica post-moderna: el conocimiento-emancipación, desde el cual la ignorancia es el colonialismo, definido por la concepción del otro como objeto, sin, consecuentemente, reconocerlo como sujeto (cf. Santos, 2003, p. 31). Tal vez es erróneo diluir la individualidad de los fenómenos observados en leyes generales, y hacer desaparecer las personas bajo determinantes, uniformes, requerimientos y convenciones ( $c f$. Touraine, 2000, p. 252). Todas las personas diseñamos. Muchas hay también que se ganan la vida por hacerlo en todo campo de actividad humana que requiera una pausada y cuidadosa consideración, entre concebir acciones, configurar medios para llevarlas a cabo, y estimar sus efectos ( $c f$. Potter, 2002, p. 10).

No pertenecemos al mundo, somos sus límites ( $c f$. Wittgenstein, 1921, p. 82, §5.632), diseñar es limitar, la experiencia de involucrarse en el acto de diseñar no es privativa de quienes diseñan profesionalmente, y desborda las actividades aficionadas del "hágalo usted mismo": casi todas las personas diseñan cotidianamente al planear la combinación de ropa que vestirán al día siguiente o preparar una comida ( $c f$. Attfield, 2000, p.17). Por eso no existe, y podemos afirmarlo categóricamente, ningún paradigma puramente objetivo, la llamada objetividad de un paradigma es sólo resultado intersubjetivo de una comunicación transferencial que llevo a que fuera valorado como tal (cf. Mires, 2002, p. 191).

Son numerosas las actividades que adelantó cada grupo y no voy a describirlas aquí, sólo a contarlas tangencialmente porque inspiran mi rapsodia, a los estudiantes de la tribu Tinkuy, y la orquesta Alpha18, siguió un tercer grupo, 5 hombres y 9 mujeres, que seleccionaron por nombre Nodus (por la raíz latina de la palabra 'nudo', y adoptaron como metáfora un gremio 
de héroes). Hay algo heroico en intentar a la vez hacer caso y desobedecer, pero, de seguro, nos creamos y experimentamos más como sujetos al rechazar o resistir la imposición. Al desfasarnos frente a nuestros propios roles sociales y decidir a qué no pertenecer, al satisfacer la necesidad de protestar, las comunidades de diseñadores requieren personas dispuestas a apartarse de la socialización pasiva, infieles al libreto social prefabricado, no para refugiarse en una contra-cultura del egoísmo, sino para generar fuerzas que les permitan construirse como sujetos originales ( $v$. Touraine, 2000, pp. 267-271).

He de confesar que, tanto como me agrada, le tengo un reparo a la palabra comunidad, aunque remite a una condición común, concentra, al menos en su sonido en español, excesivamente en la unidad: "como unidad", vislumbro una palabra que aproxime en la dispersión y variedad: 'compluridad' o "como pluralidad". Por ventura, donde las comunidades comunican, las 'compluridades', 'complurican', si en unas impera lo común, en las otras el rasgo distintivo sería lo 'complur'. Pero divago, y para explicarlo requeriré nuevos textos. Apuesto por diseñadores industriales no como expertos de un saber que niegan a otras personas, sino como facilitadores de una habilidad que todos compartimos ( $\mathrm{y}$ aplico eso de modo similar a la relación profesorestudiante). La teoría del maestro, no la veo como la disciplina obligatoria para el aprendiz, sino como la sugerencia u opción para el socio (de difundirse esta última opción, presumo, finalizaría la era de los estudiantes maniqueos, que en la dicotomía fueron acostumbrados, acaso por los profesor más gritones, a darle la razón a unos y a denegársela a otros, e inauguraría la era de los estudiantes dialógicos, prestos a articular en su discurso las razones de muchos): diseñadores de su entendimiento, más que replicadores del ajeno. Es precisamente diseñar lo que nos constituye como humanos, decir humanos es decir diseñadores, condición en que profundizan los profesionales titulados, pero común ( ¿o ¿complur?) a toda persona que proyecte disposiciones ideales futuras de elementos y recursos actuales. Cuando diseñamos algo en nuestro entorno, nos hacemos conscientes de nuestro ser, diseñar es la actividad humana fundamental, el derecho humano universal (inevitable aun cuando las personas somos recluidas en prisiones o campos de concentración); eventualmente la única división entre usuarios y diseñadores profesionales, o entre profesores de diseño y estudiantes radica en que, a menudo, algunos entre los primeros se piensan a sí mismos como élite ( $v$. Krippendorff K., 2008, minutos16:20-17:20). De vuelta a nuestro ejercicio, llama la atención que al dar a los estudiantes de los grupos partícipes en la dinámica la opción de autodenominarse en colectivo escogieron metáforas humanas (tribu, orquesta, gremio), más que físico-mecánicas (motores, máquinas, aparatos), esto lo consigno por cuanto, con frecuencia, en la generalidad de los discursos presente en el programa de diseño industrial tadeísta prevalecen pensamientos orientados y dominados por la física, envueltos en una tradición, en un mito de una era gloriosa "cuando la gente sí diseñaba bien" desde enfoques automáticos de aplicaciones forzadas de la teoría de sistemas, bajo los cuales las personas perdemos nuestra agencia y acabamos reducidas, en la más conductista vena, a predecibles dispositivos controlables de estímulo y respuesta; prefiero marcos de pensamientos biológicos y ecológicos, vivos al fin y al cabo, más favorables a teorías de la acción y a políticas de la persona ( $c f$. Touraine, 2000, p. 274).

Entre quienes han meditado el diseño, muchos abren puertas a la subjetividad, aun quienes vieron el diseño como eje de ciencias artificiales distintas a las naturales (en esa artificialidad encuentro sujetos y hacedores). Así, Herbert Simon en The Science of the Artificial, cuando señaló: "Diseña todo aquel que idea cursos de acción orientados a cambiar situaciones existentes 
en situaciones preferibles" (en Thackara, 2005, p.1), enfatizo "todo" (sin distinción) no todo aquel que aplica la teoría X o Y; y Victor Papanek, en Design for the Real World: Human Ecology and Social Change sentencia "diseñar es básico para todas las actividades humanas; situar y darle un patrón a cualquier acto humano hacia una meta deseada constituye un proceso de diseño" (p.1). Nos hacemos humanos al diseñar.

Me aparto de aquellos colegas para quienes todo encuentro con el aprendiz tiene un resultado pre-determinado: no soy amigo de la claudicación de la ignorancia estudiantil, frente al inamovible saber docente. Hay subjetividad previa a cada encuentro. Me cuesta trabajo pensar en una subjetividad pre-social, pero más aún aceptar una producción funcional de la misma según la cual las "señoras" instituciones sociales (y no las personas que las constituyen en un momento dado): universidades, familias prisiones e industrias, producen sujetos masivamente.

Somos sujetos en proceso, en curso, en deriva, y el influjo profesoral sobre el alumno puede contribuir a su configuración como sujetos autónomos o coartarla. Las prácticas materiales repetidas sobre los estudiantes en el contexto universitario ("recibir" horas y horas de clase) son procesos de producción de subjetividad. Basta con cambiar la disposición de los asientos, o el tiempo en que los protagonistas hablan, o las posiciones corporales, para innovar dicha producción de subjetividad. Con la gente de Tinkuy (2011-1), Alpha18 (2011-2) y Nodus (2011-3), intenté desarrollar formas de deslizar la producción exógena y esquemática de subjetividad, hacia la construcción autógena asumida por equipos de estudiantes que conversen para diseñar, y que puedan navegar reflexivamente entre el archipiélago de factorías de subjetividad que a veces son instauradas en las clases que instrumentalizan al otro. Durante sus vidas, los estudiantes entrarán y saldrán de diversas instituciones: universidad, industria, etc. y serán formados por ellas, pero a veces cabe recordarles que también pueden conformarlas, que incluso nos conforman a nosotros los profesores. El mito de la voz institucional, que dicta el dentro-fuera de la dinámica debe ser superado. ¿La universidad dice?, ¿el diseño dice? ¡No: las personas decimos!, hablamos, actuamos. Subjetividades fluidas. La crisis institucional radica en unos límites porosos. Me aparto de las murallas, prefiero las pieles: interfaces vivientes entre interiores y exteriores casi amalgamados. Quienes integran las comunidades conversacionales que planteo de sí-mismos por sí-mismos, donde cada quien pueda decir yo, podrían responderle a la sociedad imperial donde siempre escuchamos la voz de alguna institución, pero no la de las personas. Esa estructura institucional imperial monológica e instrumental, en prácticas y discursos es como un programa de software infectado por virus, cuyos militantes abanderados académicos modulan y anulan la subjetividad al difundir por doquier el control y la monotonía (cf. Negri y Hardt, 2000, pp. 148-149).

Frente al diseño control, propugno el diseño descontrol, como habilidad para imaginar esoaún-inexistente y hacerlo aparecer como adición con propósito en orden habitual de las cosas. El diseño del no me "des-orden", es valorado como primera tradición entre muchas tradiciones de investigación y acción desarrolladas por las personas incluidos arte, religión, educación, ciencia, tecnología, etc. Cosmologías, casas, negocios, vidas y artefactos materiales. Todo diseñado. Casi cada aspecto del mundo de la experiencia y la experimentación es diseño, importante para quienes diseñan y para quienes resultan favorecidos por su relación con lo que otros diseñan. Incluso el concepto de naturaleza es diseñado, nuestra naturaleza es diseñada y por ende diseñable ( $c f$. Nelson y Stolterman, 2003, p. 9). 


\section{Canto cuarto: los cuerpos en las palabras}

Recién, período 2012-1, acompaño a un nuevo grupo de estudiantes de diseño industrial, que transita sobre el camino recorrido, registrado (en textos, fotos y videos, y en páginas de cada grupo en la red social Facebook) por sus antecesores de la tribu Tinkuy, la orquesta Alpha18, y el gremio de héroes Nodus. El nombre que han seleccionado ellos es Noésis, según aquella intuición racional del conocimiento. A la fecha, mientras escribo esto (abril de 2012), y más allá del nombre, no han especificado aún cuál es la metáfora de su dinámica. Las actividades prosiguen, son el segundo grupo (con Nodus también lo hicimos) cuyos miembros presentan sus intenciones de proyecto en un auditorio, ante un público de un centenar de personas (profesores, compañeros, amigos, y en especial, familiares), asimismo han tenido la oportunidad de codiseñar con estudiantes de la escuela de diseño de nuevos negocios e innovación social KaosPilots, de Aarhus, Dinamarca, quienes adelantan visita de tres meses en Bogotá (entre marzo y junio de 2012). Durante los últimas semanas nos hemos preocupado por llevar su exploración fuera de las aulas, y tras tres grupos con nombre, y ocho cursos distintos de Investigación para Proyecto de Grado, serán los primeros en hacer un proyecto conjunto, aparte del de grado, y entregarlo completo, para reflexionar en la práctica sobre sus modos colectivos de diseñar.

A propósito de ello, como educador cada vez pienso más que no hay competencias esenciales iguales para todos los diseñadores, ya no me pregunto “¿cómo hago para que estos estudiantes aprendan las habilidades básicas y comprenden las competencias para diseñar?”. Ahora me digo: "¿cuál es la característica del modo como experimentan estos estudiantes de diseño la búsqueda y desarrollo de SUS competencias como diseñadores? El propósito del ejercicio de las comunidades es comprender y cultivar lo que constituye la experiencia particular dentro de cada grupo y como grupo único en sí ( $c f$. Van Manen en Satina y Hultgren, 2001, p. 531). Nos enfocamos en los pensamientos y emociones conscientes e inconscientes, y al socializarlos en clase ayudan a que cada quien se apropie de su condición mediante el lenguaje y el discurso, no mediante el mandato ( $c f$. Lupton, 1996, p. 13). La reflexión decanta al sujeto, como ser reflexivo que puede, y debe, tomarse a sí mismo como objeto de reflexión ( $c f$. Butler, 2005, p. 14). Cuando hablo de los sujetos por sí-mismos, los considero análogos al 'yo' de Touraine, dispuestos a resistir toda lógica de sistemas, prestos a transformar ipara ello son diseñadoras o diseñadores! (cf. Touraine, 2000, p. 261). En la ambigüedad, hay mucho espacio para crear, me aventuro a educar diseñadores descentrados, no totalizados, habitantes del punto de intersección entre múltiples quehaceres-saberes, liberados de los a priori, cuestionadores de prácticas hegemónicas, postuladores de alternativas. Para diseñar ninguna identidad es definitiva, siempre hay grados de apertura y ambigüedad al articular diversas posiciones ( $c f$. Mouffe, 1989, p. 35).

Las comunidades prosperan en realidades subjetivas, socialmente articuladas. No diseñamos desde 'una' verdad universal objetiva, sino desde múltiples versiones de posibilidad. Sobre construcciones propias a partir de construcciones ajenas ( $c f$. Geertz, 2003, p. 9), no hay formas únicas de darle sentido al proyecto, sólo creo en métodos emergentes al coordinar significados compartidos: intersubjectividad más que objetividad ( $c f$. Snel, 2011, p. 255). Cada quien en su cuerpo, con sus palabras, con su modo de experimentar mundos, con aquellos aspectos de su experiencia menos cuantificables desde lo sedentario ( $c f$. Satina y Hultgren, 2001, p. 522). Supuestamente, hace parte del programa general de la asignatura de IPG, en el marco de la cual adelanté la dinámica, una meditación autobiográfica, pero como lo veo, en muchos grupos, los 
colegas durante estos años han instrumentalizado este punto, no bien un estudiante localiza su participación con un suceso trascendental en su vida, se le demanda que modelen a partir de él, y que omitan todo lo anecdótico (¡de nuevo el metafísico sujeto impersonal kantiano!), hay que volver al cuerpo como vía experimental del aprendizaje, toda experiencia es corporal ( $c f$. Levin en Satina y Hultgren, 2001, p. 521). Cada voz en cada cuerpo: La subjectividad y el lenguaje son inseparables (Oosterling, 2000, p. 66). Por eso aprecio procesos de investigación situados y localización participante, subjetiva, anecdótica e intersubjetiva (¿interanecdótica’?): no hay conocimiento sin sujeto conocedor, ni siquiera en la praxis socio-científica, todo conocimiento -incluso científico- porta rasgos del sujeto que conoce y, por tanto, es irrevocable e intrínsecamente subjetivo ( $c f$. Breuer, 2003:[\$2]). Mi rapsodia invita a los estudiantes a aprender prácticas de descubrimiento, construcción, razonamiento, comprobación, invención pero sobre todo equivocación ( $c f$. Balsamo, 2000, p. 197). Que cada quien hable, con su voz: "El lenguaje es el más poderoso de todos los instrumentos de diseño, y el menos reconocido" (Fry, 1999, p. 175). Dudo mucho de los efectos de un diseño incorpóreo y exacto "en tanto forma avanzada de pensamiento que pretenda hacernos comprender a los hombres sin conocerlos" (Geertz, 2003, p. 39). Todos somos cuerpo-sujeto, hay que devolver cuerpo a la educación, conocemos el mundo en situaciones, no como circunstancias externas o locaciones físicas controlables, sino como personas situadas como sujetos con cuerpos relacionados con artefactos (y con otras personas) en entornos culturales ( $c f$. Satina y Hultgren, 2001, p. 522). Múltiples, fragmentados, contingentes. 'Subjetividad' es palabra que describe múltiples formas de entendernos a (y entre) nosotros mismos para experimentar nuestra vidas en relación con otras. Subjetividad es término más flexible que identidad, para narrarnos como personas cambiantes y contextuales, más allá de límites culturales e institucionales, asimetrías de poder y efectos de modelos hegemónicos. ( $c f$. Lupton, 1996, p.13). El cuerpo es situación, es participación para fluir en infinidad de contextos, condiciones y experiencias, nos formamos y reformamos junto a otros. (cf. Attfield, 2000, p. 238).

Me aparto de los dictadores de diseño, de su vana y esencialista búsqueda por definir perfecta, total y completamente lo que el diseño es, de su insistencia en limitar un término compuesto y expansivo. Que se esfuercen cuanto quieran por imponer, mucho dudo que encuentren categorías universalmente acordadas de 'diseño', o marcos de interpretación únicos ( $c f$. Fry, 1999, p. 4). Si hasta aquí he sido inconsistente, sin conseguir explicar la dinámica de construcción de comunidades que con los estudiantes venimos trabajando en clase de Investigación de Proyecto de Grado desde hace tres años, al menos espero expresar la que considero necesaria aproximación del universo de técnicas y mercados al de personas y culturas. Buscar el alejamiento del autoritarismo dicotómico para construirnos como sujetos (más que como personas socializadas en serie), (cf. Pérez, 2003, p. 5). Durante dos décadas he vivido en una profesión de la cual casi todos quieren ser representantes autorizados, pero muy pocos participar, cuyos miembros han fallado reiteradamente en construir coaliciones estables, y eso lo imputo a que demasiados profesores de diseño sucumbimos a la presunción cientificista y nos consagramos a un usuario abstracto como sujeto epistémico, mientras ignoramos a los estudiantes como sujetos empíricos localizados. A tantos, guardianes del conocimiento objetivo y riguroso, que se exasperan fácilmente ante la interferencia de personas particulares con valores propios cabría invitarlos a la conversación que desestabiliza el par excluyente profesor-sujeto/estudiante-objeto ( $c f$. Santos, 2003, pp. 90-91). En la feria de vanidades que se disfraza de ciencia doctrinal, reivindico 
la solidaridad basada en los despreciables conocimientos ordinarios y vulgares que como sujetos individuales creamos y usamos para dar sentido a nuestras prácticas. Los mismos que los expertos se obstinan en considerar irrelevantes, falsos e ilusorios. ¿Qué ha aportado todo ese diseño científico al enriquecimiento o empobrecimiento práctico de la vida de cada diseñador profesional? ¿Cuál (cabría hacer balances), ha sido el aporte positivo y negativo a los estudiantes de versiones eruditas de la teoría general de los sistemas, la semiótica o la estética impuestas mediante monólogos? ( $c f . p p .64-65)$.Vayamos más atrás, no a la relación de los estudiantes con la teoría objetiva, sino a la relación entre dicha teoría y la despersonalización del estudiante, o lo que es igual la ceguera docente a las singularidades de cada quien (cf. Butler, 2005, p. 10). Aquello del "perfil" no me va.

En cambio valido nuestra relación interpersonal en el tiempo, para configurarnos unos a otros como sujetos ( $c f$. Attfield, 2000, p. 7). Estimulo una sana insubordinación a la regla que desecha lo personal, valido la afirmación, el goce de sí-mismo, deshacer el poder de lo general, la fenomenología propia, la exploración investigativa. Las comunidades se configuran por la voluntad y esfuerzo de liberación de sus integrantes más que por razones o técnicas... la razón es útil cuando la localizamos e interiorizamos en nuestra subjetividad y nos genera tensiones dinámica (cf. Touraine, 2000, p. 271).

\section{Canto quinto: las palabras en los cuerpos}

Nos hacemos diseñadores al conversar, todo diseño es conversación escenificada: la innovación emerge de la conversación ('con' igual 'juntos' + 'versación' igual 'versiones': "dar versiones en compañía”, sin que impliquen acuerdos, o sean forzosamente verbales). Somos diseñadores en lo inexplorado, pues cuando manejamos problemas similares a otros previamente solucionados y sabemos cómo conversar sobre ellos, sólo somos técnicos: tenemos vocabularios al respecto para hacer distinciones precisas, compartir instrucciones correctas, e implementar medidas necesarias: por eso los controlamos. Pero nos repetimos en lo mismo, resolverlos apenas si implica diseñar. Sin diálogo no hay interacción productiva con colegas o estudiantes, todo culmina en la repetición de lo que ya es; cuando el diseño prospera en lo que será.

Frente a la estupefacción y el asombro de la novedad que da impulsar grupos a situaciones inéditas (la incapacidad de sorprenderse o confesar hacerlo es la más frecuente patología educativa en mi gremio), diseñamos artefactos jamás vistos, pues cuando carecemos de lenguaje para dar soluciones, ¡empezamos por diseñar dicho lenguaje; y coordinados por las palabras nuestros cuerpos diseñan artefactos! Primero generamos gestos, después hablamos, escribimos, describimos, nuevas ideas. Finalmente visualizamos y fabricamos. "Conversar para crear nuevos lenguajes es la tarea puntual más importante que hacemos las personas para diseñar" ( $v$. Pangaro, 2010, minutos 21:30-22:30). La razón humana o es práctica, discursiva y dialógica o no es razón. Usamos el discurso para hacer elaboración teórica, que también es una forma de práctica y actuación, la de inventar o elegir palabras justas y argumentos adecuados (que no verdaderos o falsos) ( $c f$. Ramírez, 1993, s.p).

Espero poco de la profesión si las únicas aptitudes de los profesionales consisten en manipular objetos, hablar de y con objetos y relacionarse entre sí como con objetos; sólo la interiorización de la naturaleza subjetiva fundamenta individuación ( $c f$ Touraine, 2000, p. 274). Precisamente, 
tener fuerte sentido del ser sustenta las mayores responsabilidades sociales y las capacidades de valorar el mundo como lugar habitado por otros individuos. La paradoja de nuestra individualidad es que sólo construimos dentro de un marco social (cf. Attfield, 2000, p. 141). Desde nuestros cuerpos como umbral entre nosotros y las cosas (opuestas al lenguaje y a las imágenes como representación), vehículos de nuestra auto-construcción. Corporal y subjetivamente superamos la relación objeto/sujeto. Mediante los artefactos separamos el interior (ser) del exterior (otros) y elaboramos nuestro sentido de individualidad (cf. p. 240). Los artefactos no son gente ni naturaleza, pero contienen elementos de ambos, son inquietantes interfaces, ambivalentes asuntos de amor (cf. Graves en p. 254).

Necesitamos comunidades, pues es imposible asumir solos la responsabilidad, pero la colectividad indiferenciada resulta muy abstracta para 'localizar' el compromiso (cf. Santos, 2003, p.127). Localizarnos al participar, como dijo Vico, involucrándonos comprendemos lo que los observadores no pueden ( $c f$. p.142). Cuando conversamos hay más oportunidad de renovar sistemas y producir nuevas situaciones sociales: nos afirmamos como sujetos reconociendo a otros como tales, al establecer relaciones intersubjetivas ( $c f$. Pérez, 2003, p. 8). Nos convertimos en sujetos, al hablar con otros como sujetos, sin adivinarlos (como hacemos los profesores cuando asumimos por descarte que todos nuestros estudiantes son iguales), la suposición jamás reemplazará al trato ( $c f$. p. 8).

Los significados varían. En la academia la organización social y la distribución de reconocimiento descansan sobre constituciones discursivas de posiciones subjetivas desde donde interpretamos el mundo por el cual somos gobernados. La estructura de nuestros discursos determina nuestra constitución como sujetos. Dentro del programa de diseño industrial tadeísta hay (hubo y habrá) discursos en competencia por nuestra lealtad como agentes individuales. Sus implicaciones sociopolíticas dependen de nuestra agencia como individuos subjetivamente motivados, para reproducir o transformar prácticas de diseño y la legitimidad que las apuntala. Reconocemos nuestros 'propios' intereses discursivos al convertirnos en sujetos según discursos particulares En nuestro ser convergen varios discursos, y nunca nos definimos por uno en particular. Somos discurso al pensar, hablar o escribir, expresamos posiciones específicas como sujetos pero, en diferentes momentos, abrazamos modos contradictorios de subjetividad. La inserción en el lenguaje comienza en nuestra niñez desde modelos de vida familiar e infantil. Cuanto más dogmáticos son sus discursos, quienes los soportan más niegan su propia y subjetiva parcialidad. El diseño objetivo es sólo otra versión discursiva de significado y no la 'verdad' misma; quienes abogan por él tienen intereses particulares. Merced a las formas de comunicarnos en el aula organizamos nuestra subjetividad y las capacidades mentales, físicas y emocionales individuales ( $c f$. Weedon, 1997, pp. 93-94). Una cosa es el objeto de estudio y otra el estudio de ese objeto: los datos son ficciones; 'hechos', 'formados', 'compuestos' -esa es la significación de fictio-, no necesariamente falsos, inefectivos o meros experimentos mentales de "qué pasaría sî" ( $c f$. Geertz, 2003, p. 28). Como el análisis cultural, el diseño es (o debería ser) conjeturar significaciones, estimar conjeturas y llegar a conclusiones configurativas desde las mejores conjeturas, más que el supuesto descubrimiento del continente de una significación exacta y al procesamiento de su forma perfecta (cf. ibídem).

Para entender lo que es un discurso de diseño, deberíamos no fijarnos en sus teorías, descubrimientos o inventos, ni aún en cuanto sus defensores afirman sobre él; sino atender a lo que hacen los que lo practican ( $c f$. Geertz, 2003, p. 20). Sin duda, con mi texto no planteo nada 
original, acaso sea comprensible y excusable una subjetiva mezcla de ideas, en una publicación sobre subjetividad: el reporté de mi subjetiva experiencia al intentar desarrollar comunidades con los estudiantes. Hoy considero, que más que 'tener' cuerpos, 'somos' corporalmente que nuestra subjetividad es experimentada desde el cuerpo como mediador de todo aprendizaje (cf. Satina \& Hultgren, 2001, p. 521). Además, ocasionalmente, cuando impersonalizamos el trato, las relaciones no explicitadas con los demás nos hacen opacos a nosotros mismos, dichas relaciones interpersonales despersonalizadas son el lugar donde acontece nuestra responsabilidad ética, cuando no nos percibirnos a nosotros mismos en ellas incurrimos y mantenemos inconscientemente algunas de nuestra obligaciones más importantes ( $c f$. Buttler, 2005, p.20) y más limitantes.

\section{Conclusiones}

Aguardo un tiempo en que los diseñadores produzcan artefactos que no se usen de una sola manera, sino que permitan optar para que, siempre y cuando no vaya en menoscabo de la vida humana, cada quien plasme sobre ellos y aporte el modo de usarlos que se le antoje. Trazo una sutil línea vinculante entre eso y lo que hace dos años y medio busco con los estudiantes de diseño, en el proceso de integrar comunidades alejándose de la opacidad para verse entre sí y a sí mismos, pero, he de confesarlo, tal vez la única opacidad que necesito superar es la mía, acaso el proceso me haga más nítido. Al comienzo de esta experiencia tenía cursos y estudiantes de investigación para proyecto de grado en diseño industrial, muy objetivos, genéricos y localizados en ninguna parte. Por lo mismo sumisos cuando no doctrinarios. Luego gradualmente establecimos vínculos, y configuramos la tribu Tinkuy, la orquesta Alpha18, el gremio Nodus y lo que quiera que sea Noésis, en total 18 hombres y 41 mujeres a quienes trate de conocer y entusiasmar con la localización participante. Y de quienes aprendí montones. Acabo sin exponer lo que diseñaron, pero dando cuenta de cuánto me enseñaron, y tras acaso haber pormenorizado, un poco, cómo lo hicieron; eso sí con ganas de comentar algo, un detalle sutil: al final de cada curso, los estudiantes entregan una memoria de proyecto de grado que en la Tadeo llamamos "sistema de registro", pues bien, mientras elaboraba este texto, al tiempo que preparaba clases para el actual grupo (Noésis), advertí que dicho trabajo que por separado soporta la tradición del individualismo y el monólogo, bien podría ser un símbolo comunal de encuentro y, tras casi tres años, pensé por vez primera, en lugar de solicitarle a los 13 estudiantes, 13 trabajos distintos, en invitarlos a elaborar 13 copias de un mismo trabajo, un libro conjunto y múltiple que los contuviera a todas, o mejor 14 (incluida una para mí), ojalá ese enlace duradero entre documentos, presagie una enlace duradero entre personas. Este, por supuesto, no es ni el fin, ni el principio del fin, y ni siquiera el fin del principio, si acaso es el principio del principio de $\mathrm{mi}$ rapsodia para los sujetos por sí mismos.

Algún día o noche, espero, se convierta en rapsodia de esos mismos sujetos por sí mismos. 


\section{Referencias Bibliográficas}

Attfield, J. (2000). Wild things: the material culture of everyday life. Oxford: Berg.

Balsamo, A. (2000). Teaching in the belly of the beast: femism un the best of all places en Marchessault, J. y Sawchuk, K. (2000). Wild science: reading feminism, medicine, and the media. London: Routledge. Pp. 185-214. [En linea] Disponible en http://www.designingculture.net/ wordpress/wp-content/uploads/2010/06/Balsamo_2000_BellyOfTheBeast.pdf (Recuperado el 04/03/2012

Breuer, F. (2004). Lo subjetivo del conocimiento socio-científico y su reflexión: ventanas epistemológicas y traducciones metodológicas [44 párrafos $\$ \$$ ]. Forum Qualitative Sozialforschung / Forum: Qualitative Social Research, 4(2), Art. 25. Disponible en: http://nbn-resolving.de/ urn:nbn:de:0114-fqs0302258 (Recuperado el 01/03/2012).

Butler, J. (2005). Giving an account of oneself. New York: Fordham University Press.

Das, V. (2007). Life and words: violence and the descent into the ordinary. Berkeley: University of California Press.

Fry, T. (1999). A new design philosophy an introduction to defuturing. Sydney: UNSW Press.

Geertz, C. ([1973], 2003). La interpretación de las culturas. Barcelona: Gedisa.

Gibson, J. J. ([1979],1986). The ecological approach to visual perception. New York: Psychology Press.

Jung, C. G. (2009 [1928]). Las relaciones entre el yo y el inconsciente. Barcelona: Paidós Ibérica.

Krippendorff, K. (2009). On communicating: Otherness, meaning, and information. Bermejo, F. (edit) London: Routledge.

(2008), Scientific Research, and the Exploration, Creation, and Communication of Design Space [conferencia en formato de video] en Creating new realities today BIRD DESIGN RESEARCH SYMPOSIUM, Basilea, Suiza, abr. 4 y 5. Minutos 16:00-17:00. Disponible en http:// symposium.idk.ch/videos.php (Recuperado el 04/03/2012).

(2007) The Cybernetics of Design and the Design of Cybernetics en Kyberne-

tes, Vol. 36, No. 9/10, 2007, pp. 1381-1392. [En línea] ScholarlyCommons. Disponible en: http://repository.upenn.edu/asc_papers/48/ (Recuperado el 05/03/2012) (paginación del archivo digital).

Lupton, D. (1996). Food, the body, and the self. London: Sage Publications.

Michl, J. (2008 [2002]). Sobre el diseño como rediseño»: una exploración de un problema olvidado en la enseñanza de diseño. Disponible en http://www.ramona.org.ar/node/20064 revista argentina de artes visuales Ramona 79, marzo, (recuperado el 19/03/2012) [en línea] traducción parcial del artículo Seeing design as redesign, origin en Scandinavian Journal of Design History 12, 2002, pp. 7-23; ver http://www.designaddict.com/essais/michl.html recuperado 19/03/2012 [en línea]

Mires, F. (2002). Crítica de la razón científica. Caracas: Editorial Nueva Sociedad.

Mouffe, C. (1989) [traducción de Holdengräber, Paul] Radical democracy: modern or postmodern en Social Text, No. 21. Universal Abandon? The Politics of Postmodernism (pp. 31-45)

Negri, A. y Hardt, M. (2000). Imperio. Traducción de Eduardo Sadier de la edición de Harvard University Press, Cambridge, Massachussets, 2000. 
Nelson, H. G. y Stolterman, E. (2003). The design way: intentional change in an unpredictable world : foundations and fundamentals of design competence. Englewood Cliffs, N.J.: Educational Technology Publications.

Nietzsche, F. W. ([1883-1885] s.f). De las mil metas y de la única meta en Así habló Zaratustra, LIBRTOdot.com [En línea] Disponible en: http://www.enxarxa.com/biblioteca/NIETZSCHE \%20Asi\%20hablo\%20Zaratustra.pdf Pp. 33-35 (Recuperado el 05/03/2012).

([1883-1885]1982). "De los mil y un objeto" en Así hablaba Zaratustra. Madrid: EDAF. Pp. 58-60.

Nitzche, R. (2012) Empatia e design na evolução humana en FOROALFA Disponible en: http:// foroalfa.org/articulos/empatia-e-design-na-evolucao-humana (Recuperado el 08/04/2012).

Oosterling, H. (2000) A Culture of the 'Inter': Intercultural explorations on Japanese thought en Kimmerle, Heinz y Oosterling, Henk. (2000). Sensus communis in multi- and intercultural perspective: on the possibility of common judgments in arts and politics. Würzburg: Königshausen \& Neumann. Pp. 61-85.

Pangaro, P. (2010). Rethinking Design Thinking en PICNIC '10 video [en línea] Disponible en: http://vimeo.com/15836403 (Recuperado el 05/03/2012).

Pérez, G. (2003). "Sujeto desgarrado" y modernidad. Contribución de Alain Touraine a la reflexión psicológica sociocultural sobre la subjetividad en el mundo contemporáneo» en Psicología y Ciencia Social Vol. 5 No. 1, sin mes, pp. 3-10 [en línea]. Disponible en: http://redalyc. uaemex.mx/src/inicio/ArtPdfRed.jsp?iCve=31411284001 ISSN 1405-5082 (Recuperado el $11 / 03 / 2012)$

Potter, N. ([1969]2002). What is a designer: things, places, messages. London: Hyphe.

Ramírez, J. L. (1993). Democracia como estructura y como forma de vida, Conferencia Variedades y límites de la democracia, Universidad Internacional, Menéndez Pelayo, Valencia, [en línea] Disponible en http://www.ub.edu/geocrit/sv-68.htm (Recuperado el 08/09/2011).

Rapsodia (2011, 16 de diciembre) [en línea] en Wikipedia, La enciclopedia libre. http://es.wikipe dia.org/w/index.php?title=Rapsodia\&oldid=52260876 (Recuperado el 19/03/2012).

Rapsodia-eti. (s. f.) (etimología) [en línea] Disponible en http://etimologias.dechile.net/?rapso dia (Recuperado el 19/03/2012).

Rapsodia-sig. (s. f.) (significado) Diccionario de la Real Academia Española (DRAE) [en línea] Disponible en http://buscon.rae.es/draeI/ (Recuperado el 19/03/2012).

Santos, Boaventura de Sousa. (2003). Crítica de la razón indolente. Para un nuevo sentido común: la ciencia, el derecho y la política en la transición paradigmática. Palimpsesto, 18. Bilbao, Desclée de Brouwer.

Satina, B. y Hultgren, F. (2001). The Absent Body of Girls Made Visible: Embodiment as the Focus in Education en Studies in Philosophy and Education 20: 521-534. ( 2001 Kluwer Academic Publishers. Printed in Netherlands

Snel, J. M. C. (2011). For the love of experience changing the experience economy discourse. disertación académica para la obtención del doctorado en la Universidad de Amsterdam [S.l]: [s.n.]. Thackara, J. (2005). In the bubble: Designing in a complex world. Cambridge, Mass: MIT Press. Touraine, A. (2000). [traducción de Bixio, Alberto Luis]. Crítica de la modernidad. México: Fondo de Cultura Económica. 
Virilio, P. (1994). The vision machine. Bloomington: Indiana University Press.

Weedon, C. (1997). Feminist practice and poststructuralist theory. Oxford: Blackwell.

Wittgenstein, L. (1921). Tractatus logico-philosophicus. Edición Electrónica disponible en: www. philosophia.cl /Escuela de Filosofía Universidad ARCIS.

Summary: In this subjective, personal, localized and participant reflection on subjects and subjectivities, talking my educational experience with industrial design students at the University Jorge Tadeo Lozano in Bogota, Colombia, in the same subject: Undergraduate Research Project (GEM) after nearly three years (2009-2012) dedicated to fostering conversations and approaches in the classroom, I call dynamic design to build strong communities intersubjective links. My argument, not linear, but fragmentary and circular (from here the name Rhapsody), I raise from authors who consider advocates of both subjectivity as empirical subjects by name (Alain Touraine, Judith Bulter, Boaventura de Sousa Santos, Tony Fry, Klaus Krippendorff, Judith Bulter, Veena Das, Clifford Geertz, etc.). The five chapters: 1 . The personality consumption, 2. Artifacts and not objects. 3. Design as a condition of subjection, 4 . The bodies in the words and 5. The words in the body, drew up a manifesto in first person (participating locations to explain why I believe that all design, the more professional more subjective and intersubjective, arises from the encounter between people located and also participants.

Key words: 'compluridad' (as plurality) - dialogue - design - language - participation - subject.

Resumo: Nesta subjetiva, pessoal, localizada e participante meditação sobre sujeitos e subjetividades, refiro minha experiência educativa com estudantes de design industrial da Universidade Jorge Tadeo Lozano de Bogotá, Colômbia, da mesma matéria: Pesquisa para Projeto de Graduação (IPG), após quase três anos (2009-2012) dedicados a propiciar conversações e aproximações na aula, em dinâmicas que denomino de design de comunidades para consolidar fortes vínculos intersubjetivos. Meu argumento, não lineal, senão fragmentário e circular (daí o nome "rapsódia") o abordo desde autores considerados defensores, tanto da subjetividade como de sujeitos empíricos com nome e sobrenome (Alain Touraine, Judith Bulter, Boaventura de Sousa Santos, Tony Fry, Klaus Krippendorff, Judith Bulter, Veena Das, Clifford Geertz, etc.). Os cinco cantos: 1 . O consumo da personalidade, 2. Artefatos e não objetos, 3. Design enquanto condição de subjetivação, 4 . Os corpos nas palavras y 5 . As palavras nos corpos, constituem um manifesto que elaborei em primeira pessoa (localização participante) para explicar por que considero que todo design, quanto mais profissional, mais subjetivo e intersubjetivo, surge do encontro entre pessoas assim mesmo localizadas e participantes.

Palavras chave: 'compluralidad' (como pluralidade) - diálogo - design - linguagem - participação - sujeito. 